\title{
COOPERAÇÃO: UM MÉTODO PIAGETIANO NA FORMAÇÃO DE PROFESSORES
}

\author{
COOPERATION: A PIAGET METHOD IN TEACHER TRAINING
}

Silvana Corbellini ${ }^{1}$

\begin{abstract}
RESUMO: Este trabalho é fruto de investigação desenvolvida entre os anos de 2018 e 2020, junto a estudantes de licenciaturas que cursavam disciplinas na Faculdade de Educação (FACED) de uma universidade federal localizada no estado do Rio Grande do Sul. O objetivo foi analisar como ocorre o método da cooperação nas trocas interpessoais durante a formação inicial de professores de cursos de licenciaturas nas disciplinas ministradas na Faculdade, visando auxiliar na construção de um processo de ensino e aprendizagem no qual se possa contemplar a cooperação, fomentando o aprimoramento da formação de professores. A metodologia utilizada foi a pesquisa de campo como técnica de coleta de dados por meio de questionários. Os sujeitos da pesquisa foram 127 estudantes e seis professores de sete turmas de disciplinas da FACED. Os dados foram produzidos por meio de dois questionários com os estudantes, sendo que o primeiro foi aplicado no início do semestre e o segundo, no final do semestre, além de questionário aplicado junto aos professores. A fundamentação teórica que norteou o trabalho foi a Epistemologia Genética de Jean Piaget. Os resultados apontam que há cooperação entre professores, entre professores e estudantes, entre estudantes e estudantes, ocorrendo de diversas maneiras e com diversos níveis e, que existem estratégias que podem ser utilizadas em sala de aula para fomentar a cooperação e qualificar a educação.
\end{abstract}

Palavras-chave: Cooperação. Formação de Professores. Epistemologia Genética.

\begin{abstract}
This work is the result of an investigation carried out between 2018 and 2020, with undergraduate students who attended courses at the Faculty of Education (FACED) of a Federal University located in the state of Rio Grande do Sul. The objective was to analyze how the method of cooperation in interpersonal exchanges during the initial training of teachers in undergraduate courses in subjects taught at the Faculty occur, aiming to assist in the construction of a teaching and learning process in which cooperation can be contemplated, fostering the improvement of teacher training. The methodology used was field research as a data collection technique through questionnaires. The research subjects were 127 students and six professors from seven classes of FACED disciplines. Data were produced through two questionnaires with students, the first being applied at the beginning of the semester and the second at the end of the semester, in addition to a questionnaire applied with the professors. The theoretical foundation that guided the work was Jean Piaget's Genetic Epistemology. The results show that there is cooperation between teachers, between teachers and students, between students and students, occurring in different ways and at different levels, and that there are strategies that can be used in the classroom to foster cooperation and qualify education.
\end{abstract}

Keywords: Cooperation. Teacher training. Genetic Epistemology.

\section{Introdução}

Estudar a cooperação e procurar maneiras de implementá-la na sociedade é uma árdua tarefa, e na educação é um espaço no qual podemos começar a refletir melhor sobre

\footnotetext{
1 Universidade Federal do Rio Grande do Sul, Brasil. E-mail: silvanacorbellini@gmail.com

(i) https://orcid.org/0000-0002-3335-0387
}

- Informações completas da obra no final do artigo 
esse tema. O mundo carece de relações solidárias, o que nesse momento de pandemia do Covid-19 mostra-se mais veemente e tornou emergente a necessidade de um coletivo, de trabalhos em parcerias, de compartilhamentos de conhecimentos, o que nos aponta para a cooperação como um caminho necessário para minimizar os efeitos advindos dessa tragédia e para possibilitar novos arranjos e construções de conhecimentos.

Conforme já apontado em outro texto (CORBELLINI, 2020, p. 120):

Em tempos de pandemia, em que a população se encontra em sofrimento psíquico, vulnerável, ater-se aos conteúdos pode ser um não senso. Hoje, precisamos auxiliar aos nossos estudantes a adquirirem condições de compreensão do mundo, das relações e de lidar com o que está ao seu redor. A grande aprendizagem desse momento, pode ser a potencialidade dessas competências o que irá ajudá-los a desenvolver a sua autonomia, a criticidade, a criatividade e a cooperação. Essas competências irão possibilitar para que se tenham melhores condições de responder aos novos problemas que se apresentarem.

Especificamente neste artigo, pretende-se apresentar a discussão do estudo que adotou como objetivo geral analisar como ocorre o método da cooperação nas trocas interpessoais durante a formação inicial de professores de cursos de licenciatura em algumas das disciplinas ministradas na Faculdade de Educação. Tal objetivo se desdobra nos seguintes objetivos específicos: identificar observáveis de cooperação no processo de ensino e aprendizagem em disciplinas de licenciaturas; mapear as atividades que fomentam ou limitam a ocorrência do método de cooperação no processo de ensino e aprendizagem em disciplinas ministradas de licenciaturas; e investigar as implicações para a formação de professores decorrentes da ocorrência ou não, do método da cooperação no processo de ensino e aprendizagem de disciplinas de cursos de licenciaturas.

A fundamentação teórica que norteou o desenvolvimento da investigação que deu origem a este artigo foi a Epistemologia Genética de Jean Piaget. A metodologia utilizada foi a pesquisa de campo. Os sujeitos da investigação foram 127 alunos e seis professores de sete turmas de disciplinas de cursos de licenciaturas da FACED. Os dados foram produzidos por meio de dois questionários aplicados aos estudantes, sendo que o primeiro foi aplicado no início do semestre e o segundo, no final do semestre, além de um questionário aplicado aos professores no início do semestre. Buscou-se, desta forma, compreender como ocorre o método de cooperação nas trocas interpessoais durante a formação inicial de professores de cursos de Licenciaturas, visando auxiliar na construção de um processo de ensino e aprendizagem no qual se possa contemplar a cooperação, fomentando o aprimoramento da formação de professores. 


\section{Desenvolvimento teórico}

Ao se procurar compreender a construção da cooperação dentro da Educação, refletindo sobre suas possibilidades e suas dificuldades, sabemos de antemão que existem vários fatores que fazem parte deste processo, tais como: o papel do professor, a concepção epistemológica que subjaz a sua prática, bem como a do aluno; os processos avaliativos, coercitivos, limitações dos alunos em trabalhar de forma cooperativa, falta de autonomia, etc. (CORBELLINI, 2019).

Pesquisadores, tais como Isotani (2009), Harasim (2000), Pallof e Pratt (2002), Campos et all. (2003), Kenski (2003) entre outros, têm se dedicado ao estudo da colaboração e cooperação na educação. Os entendimentos existentes para esses termos são diversos, por isso, é importante frisar que trabalhamos com o conceito piagetiano de cooperação, que será especificado a seguir.

Para tanto, é importante a reflexão sobre a formação de professores para que se alcance um trabalho cooperativo em sala de aula. Piaget (1977) ao falar sobre o papel do professor defende o ponto de vista de que ele deve ser um pesquisador, construindo problemas por meio dos quais o sujeito exercerá a sua capacidade de reflexão.

[...] é evidente que o educador continua indispensável, a título de animador, para criar as situações, e armar os dispositivos iniciais capazes de suscitar problemas úteis à criança, e para organizar, em seguida, contraexemplos que levem à reflexão e obriguem ao controle das situações demasiado apressadas: o que se deseja é que o professor deixe de ser apenas um conferencista e que estimule a pesquisa e o esforço, ao invés de se contentar com a transmissão de soluções já prontas (PIAGET, 1977, p. 18).

Dessa forma, o papel do professor mostra-se como um dos elementos fundamentais para o desenvolvimento dos sujeitos. Piaget (1998) apresenta a cooperação como uma superação das relações heterônomas, mas sem que estas sejam substituídas totalmente e, além disto, trata a cooperação como assunto tanto moral como intelectual. Nesse sentido, o professor não pode se colocar no lugar de detentor de saber ou daquele que detém o poder na sala de aula. O autor enfatiza o "método da cooperação", comparando-o a uma atitude científica, a qual requer a descentração do seu ponto de vista para conhecer os demais e coordená-los. Alerta para a necessidade da manutenção do ponto de vista próprio, como uma garantia de se manter próximo ao real, uma vez que este é particular.

O método da cooperação caracteriza-se da seguinte forma: dar conta de duas tendências, a de aceitar o real como lhe parece e, a de corrigir o real, coordenando-o com 
diferentes perspectivas, compreendendo que o ponto de vista próprio é apenas mais um possível entre os demais e que não pode ser visto como absoluto, nem pode ser renunciado por completo, mas deve ser relacionado aos demais, na busca da manutenção da lógica (CAMARGO; BECKER, 2012). Salientamos que uma proposição não pode ser ignorada, deve ser considerada a cada nova fundamentação de novas proposições: é a lógica da reciprocidade ou, a "lógica das relações". Esta lógica, então, consiste em corrigir e superar o ponto de vista imediato, para situá-lo num sistema de conjunto capaz de coordenar essa perspectiva particular com um número crescente de visões diferentes (PIAGET, 1998).

Para que a cooperação seja efetivada, Piaget (1973) indica a necessidade de que três condições sejam cumpridas: (1) a existência de uma escala comum de valores intelectuais, que possam ser expressos através de símbolos comuns unívocos; (2) a conservação das escalas de valores, gerando obrigações para aqueles que as reconhecem; e, (3) a atualização constante dos valores construídos, sem contradições de ambas as partes.

Piaget (1973) refere que essas três condições ocorrem somente quando as trocas são cooperativas, e no equilíbrio das trocas expressam os agrupamentos operatórios, que são assim conceituados:

O agrupamento não é assim senão um sistema de substituições possíveis, seja no
centro de um pensamento individual (operações da inteligência), seja de um
indivíduo a outro (cooperação). Estas duas espécies de substituições constituem
então, uma só lógica geral, ao mesmo tempo coletiva e individual, que caracteriza
a forma de equilíbrio comum tanto às ações cooperativas quanto às individualizadas
(PIAGET, 1973, p. 196).

Continuando, Piaget (1973) afirma que a aprendizagem cooperativa é a forma de aprender a aprender por meio de atividades (ações e operações) - sejam estas interações com objetos físicos e culturais individuais ou coletivas. Assim, estudantes e professores, baseados em regras autônomas e no respeito mútuo entre todos que fazem parte do coletivo de aprendizagem, interagem para estabelecer trocas. A cooperação, então, é considerada como a coordenação do conjunto de trocas de ações e operações que os indivíduos realizam entre si quando desejam alcançar o mesmo objetivo.

Piaget destaca a necessidade de estar-se "entre pares", diferenciando da coerção para que ocorra a cooperação. Entende a cooperação como um método que nos força a considerar, incessantemente, as verdades reconhecidas, de maneira que conduza a um acordo sempre maior de opiniões e de pontos de vista. Desta forma, a cooperação mantém- 
se em equilibrações. Desta maneira, a cooperação é um processo que inter-relaciona as proposições de todos os sujeitos, sendo “[...] efetivamente criadora, ou, o que dá na mesma, que ela constitui a condição indispensável para a constituição plena da razão" (PIAGET, 1998, p. 144). Condizente com este aspecto, na investigação do método da cooperação entre os estudantes, pode-se concluir que este é, antes de tudo, um processo a ser construído e não um produto a ser ofertado (CORBELLINI, 2019).

Piaget (1998) refere que este sujeito (estudantes e professores) é, também, um sujeito que precisa aprender a ser autônomo. Afirma que a educação pode ser uma ferramenta nesta construção, através do uso de trabalhos em grupos, do self government e das trocas entre pares, que auxiliarão no desenvolvimento da autonomia dos sujeitos, fruto do método da cooperação. E, afirma que: "[...] foi pelo atrito incessante com outrem, pela oposição das vontades e das opiniões, pela troca e pela discussão, pelos conflitos e pela compreensão mútua que todos nós aprendemos a nos conhecer" (PIAGET, 1998, p. 142).

Para tanto, é importante a reflexão sobre a formação de professores para que se alcance um trabalho cooperativo em sala de aula. Piaget (1977) ao falar sobre o papel do professor defende o ponto de vista de que ele deve ser um pesquisador, construindo problemas por meio dos quais o sujeito exercerá a sua capacidade de reflexão.

[...] é evidente que o educador continua indispensável, a título de animador, para
criar as situações, e armar os dispositivos iniciais capazes de suscitar problemas
úteis à criança, e para organizar, em seguida, contraexemplos que levem à reflexão
e obriguem ao controle das situações demasiado apressadas: o que se deseja é
que o professor deixe de ser apenas um conferencista e que estimule a pesquisa e
o esforço, ao invés de se contentar com a transmissão de soluções já prontas
(PIAGET, 1977, p. 18).

Dessa forma, o papel do professor mostra-se como um dos elementos fundamentais para o desenvolvimento dos sujeitos. Piaget (1998) apresenta a cooperação como uma superação das relações heterônomas, mas sem que estas sejam substituídas totalmente e, além disto, trata a cooperação como assunto tanto moral como intelectual. Nesse sentido, o professor não pode se colocar no lugar de detentor de saber ou daquele que detém o poder na sala de aula. O autor enfatiza o "método da cooperação" comparando-o a uma atitude científica, a qual requer a descentração do seu ponto de vista para conhecer os demais e coordená-los. Alerta para a necessidade da manutenção do ponto de vista próprio, como uma garantia de se manter próximo ao real, uma vez que este é particular. O "método 
da cooperação" é mencionado como "lógica das relações", sendo esta lógica, produto deste método. Piaget (1973) explica o "método da cooperação" como sendo um instrumento da cooperação e apresenta três condições para que se efetive: (1) desfazer-se do egocentrismo intelectual e moral; (2) libertar-se das coerções sociais; e (3) método da reciprocidade.

O método da cooperação caracteriza-se da seguinte forma: dar conta de duas tendências, a de aceitar o real como the parece e, a de corrigir o real, coordenando-o com diferentes perspectivas, compreendendo que o ponto de vista próprio é apenas mais um possível entre os demais e que não pode ser visto como absoluto, nem pode ser renunciado por completo, mas deve ser relacionado aos demais na busca da manutenção da lógica. Salientamos que uma proposição não pode ser ignorada, deve ser considerada a cada nova fundamentação de novas proposições: é a lógica da reciprocidade ou, a "lógica das relações". Esta lógica então consiste em corrigir e superar o ponto de vista imediato, para situá-lo num sistema de conjunto capaz de coordenar esta perspectiva particular com um número crescente de visões diferentes (PIAGET, 1998).

Para que a cooperação seja efetivada, Piaget (1973) indica a necessidade de que três condições sejam cumpridas: (1) a existência de uma escala comum de valores intelectuais, que possam ser expressos através de símbolos comuns unívocos; (2) a conservação das escalas de valores, gerando obrigações para aqueles que as reconhecem; e, (3) a atualização constante dos valores construídos, sem contradições de ambas as partes.

Piaget (1973) refere que essas três condições ocorrem somente quando as trocas são cooperativas, e no equilíbrio das trocas expressam os agrupamentos operatórios, que são assim conceituados:

O agrupamento não é assim senão um sistema de substituições possíveis, seja no centro de um pensamento individual (operações da inteligência), seja de um indivíduo a outro (cooperação). Estas duas espécies de substituições constituem então, uma só lógica geral, ao mesmo tempo coletiva e individual, que caracteriza a forma de equilíbrio comum tanto às ações cooperativas quanto às individualizadas (PIAGET, 1973, p. 196).

Continuando, Piaget (1973) afirma que a aprendizagem cooperativa é a forma de aprender a aprender por meio de atividades (ações e operações) - sejam estas interações com objetos físicos e culturais individuais ou coletivas. Assim, estudantes e professores, baseados em regras autônomas e no respeito mútuo entre todos que fazem parte do 
coletivo de aprendizagem, interagem para estabelecer trocas. A cooperação, então, é considerada como a coordenação do conjunto de trocas de ações e operações que os indivíduos realizam entre si quando desejam alcançar o mesmo objetivo.

Piaget destaca a necessidade de estar-se "entre pares", diferenciando da coerção para que ocorra a cooperação. Entende a cooperação como um método que nos força a considerar, incessantemente as verdades reconhecidas, de maneira que conduza a um acordo sempre maior de opiniões e de pontos de vista, desta forma, a cooperação mantémse em equilibrações. Desta maneira, a cooperação é um processo que inter-relaciona as proposições de todos os sujeitos, sendo "[...] efetivamente criadora, ou, o que dá na mesma, que ela constitui a condição indispensável para a constituição plena da razão" (PIAGET, 1998, p. 144). Condizente com este aspecto, na investigação do método da cooperação entre os estudantes, pode-se concluir que este é, antes de tudo, um processo a ser construído e não um produto a ser ofertado (CORBELLINI, 2019).

Piaget (1998) refere que este sujeito (estudantes e professores) é, também, um sujeito que precisa aprender a ser autônomo. Afirma que a educação pode ser uma ferramenta nesta construção, através do uso de trabalhos em grupos, do self government e das trocas entre pares, que auxiliarão no desenvolvimento da autonomia dos sujeitos, fruto do método da cooperação. E, afirma que: "[...] foi pelo atrito incessante com outrem, pela oposição das vontades e das opiniões, pela troca e pela discussão, pelos conflitos e pela compreensão mútua que todos nós aprendemos a nos conhecer" (PIAGET, 1998, p. 142).

\section{Metodologia}

A pesquisa teve seu início em 2018 e, no primeiro momento realizou-se um estudo piloto com cinco turmas de licenciaturas da FACED. Foram aplicados questionários com estudantes e professores no semestre 2018/1. A partir da análise desses dados, foi necessária uma readequação dos instrumentos. Cumpre-se que, tanto nesse estudo piloto, como no seguimento da pesquisa foram solicitados os Termos de Consentimento Livre e Esclarecido (TCLE) dos estudantes e professores. Os professores foram convidados via email a participarem da pesquisa, bem como, obteve-se o termo de anuência da instituição.

Para a reformulação dos instrumentos, procurou-se, a partir dos dados levantados e de uma aproximação teórica, construir questões que fossem mais elucidativas à nossa 
pesquisa. Com os novos instrumentos, enviou-se novamente convites via e-mail para os professores da FACED, e a partir das disponibilidades foi feita uma logística que contemplasse os horários dos professores e da pesquisadora. No início do semestre de 2018/2 foram aplicados os questionários em sete turmas, no total de 127 estudantes, acompanhados dos respectivos TCLEs. No final do semestre foi aplicado o segundo questionário, alcançando-se um total de 80 estudantes. Os estudantes eram de diversas licenciaturas, tais como Pedagogia, Ciências Biológicas, Filosofia, Matemática, Física, Educação Física, Química, Ciências Sociais, etc. e a idade varia entre 18 anos e 55 anos. O tempo no curso também apresentou variações, contemplando desde estudantes calouros até formandos.

Foram aplicados os questionários com os sete professores das turmas, acompanhados dos respectivos TCLEs. Destaca-se que um dos professores não retornou o seu questionário. Os professores são de diversas formações, como psicologia, pedagogia, história e filosofia; todos possuem doutorado, têm idade entre 48 e 72 anos e tempo de docência de 21 a 48 anos. As turmas são assim constituídas:

Quadro I - Dados das Disciplinas

\begin{tabular}{|c|c|c|c|}
\hline Disciplina & Professor(a) & $\begin{array}{c}\text { Questionário Inicial } \\
\text { Número de alunos }\end{array}$ & $\begin{array}{c}\text { Questionário Final } \\
\text { Número de alunos }\end{array}$ \\
\hline D1 & P1 & 18 & 10 \\
\hline D2 & P2 & 21 & 20 \\
\hline D3 & P3 & 10 & 05 \\
\hline D4 & P4 & 08 & 08 \\
\hline D5 & P5 & 38 & 07 \\
\hline D6 & P6 & 12 & 10 \\
\hline D7 & P7 & 20 & 20 \\
\hline
\end{tabular}

Fonte: Organizado pela autora.

Os dados são apresentados em três tópicos de análise, relativos aos dois questionários aplicados nos estudantes e ao questionário aplicado aos docentes. Ao final, desenvolvem-se as análises do conjunto de dados, procurando uma compreensão da ocorrência do método de cooperação, a partir do ponto de vista dos participantes da pesquisa.

\section{Apresentação e Análise dos dados}

Foram entrevistadas sete turmas com um total de seis professores, pois um não entregou o seu questionário. No primeiro questionário, aplicado nos estudantes no início do 
semestre, obtivemos 127 respondentes. No questionário 2, aplicado nos estudantes ao final do semestre, obtivemos 80 respondentes. Este decréscimo se deu devido ao fato de que havia estudantes que não estavam mais cursando as disciplinas, além de outros que já haviam sido aprovados e não compareceram aos encontros finais.

Como códigos, utilizamos a letra D seguida dos números, para a disciplina (D1, D2, D3, D4, D5, D6 e D7). Da mesma forma, para os professores, segue-se o mesmo padrão, alterando-se a letra para P. Para os estudantes, optou-se por deixar a disciplina a que pertencem, o curso e o semestre, pois consideramos esses dados importantes nas análises e na compreensão das diferenças algumas vezes, da área original. Então, por exemplo, fica de um estudante: D7, Pedagogia, $3^{\circ}$ semestre.

\section{Dados questionário inicial dos estudantes}

O questionário inicial compunha-se de cinco questões dissertativas, que pretendem compreender a visão dos estudantes do processo de ensino e aprendizagem, sua participação em sala de aula com professores e colegas, os valores e o que entendem por cooperação.

A partir dos questionários, organizaram-se as repostas, visando obter um panorama geral do entendimento dos discentes sobre as questões solicitadas. Dessa forma, a partir da questão 1 - Como você acredita que aprende? Em que tipo de aulas você aprende? conseguimos elencar as seguintes percepções de como os estudantes acreditam aprenderem: seminários, discussão, trocas (professores e colegas), aulas expositivas seguidas de debates, contextualização com a vida (relatos, compartilhamento de experiências); práticas (dinâmicas, jogos, trabalhos em grupo); leitura individual; realizando sínteses/esquemas. Aqui, é importante observar que, em cada turma, os estudantes procuravam citar o que havia sido desenvolvido na disciplina. Além disso, destaca-se que surgem diferenças entre as formas de ensinar de cada curso das licenciaturas, sendo observadas repetição, como uma das formas, principalmente na área da matemática; debates, entre a área das Ciências Sociais e visuais, entre a área de Artes. Além disso, um ponto que se salienta é de que um tópico não exclui o outro e que, em nenhum momento, a aula expositiva apareceu como uma resposta única. 
Para ilustrar esse tópico, citamos um estudante da D7, Pedagogia, $3^{\circ}$ semestre que diz: Acredito que aprendemos muito com a escuta do outro, aprendo em debates, em grupo, etc.

Na questão 2 - Considera importante a realização de trocas entre os colegas? E com o professor? Por quê? - as respostas indicam de forma unânime a importância que os estudantes dão para as trocas entre os colegas. Em relação às trocas entre professor e estudantes, somente uma estudante referiu sentir-se mais à vontade com os colegas.

Os motivos citados para a importância das trocas são: auxilia no entendimento, pontos de vista diferentes, aplicações práticas, linguagem dos colegas é mais fácil de compreender, auxilia contra a timidez, troca de informações e é o que faz aprender. Esses tópicos apontam para uma concepção epistemológica construtivista como forma de aprender. Podemos ilustrar com os seguintes recortes:

D5, Matemática, $2^{\circ}$ semestre: Sim, é sempre muito interessante ouvir a opinião dos colegas, já que algumas vezes os pensamentos são diferentes dos meus. Penso que após ouvirmos uma opinião diferente da nossa nós refletimos sobre a nossa opinião e a dos outros e às vezes modificamos nossa ideia inicial. Ouvir o que o professor tem a dizer normalmente é uma experiência que nos faz crescer intelectualmente e como pessoas. Sempre podemos aprender muito com os outros e aprendemos a respeitar as ideias diferentes das nossas.

D6, Biologia, $7^{\circ}$ semestre: $A$ troca de informações entre os colegas é importante para reforçar e ressignificar as informações aprendidas através do professor. As trocas entre professor - aluno são importantes para esclarecimento de dúvidas e argumentações.

A questão 3 - Você participa ativamente das aulas? Se sim, como? Se não, por que? - apresentou respostas diversas que foram agrupadas em um quadro para visualização.

Quadro II - Respostas à questão 3

\begin{tabular}{|c|c|c|c|c|}
\hline Disciplina & $\begin{array}{c}\mathbf{N}^{\circ} \text { de } \\
\text { estudantes }\end{array}$ & Sim & Não & Depende \\
\hline 1 & 18 & 11 & 7 & 0 \\
\hline 2 & 21 & 10 & 5 & 6 \\
\hline 3 & 10 & 8 & 1 & 1 \\
\hline 4 & 8 & 5 & 1 & 2 \\
\hline 5 & 38 & 18 & 18 & 2 \\
\hline 6 & 12 & 8 & 4 & 0 \\
\hline 7 & 20 & 14 & 5 & 1 \\
\hline
\end{tabular}

Fonte: Organizado pela autora.

Entre os motivos citados para a participação daqueles que responderam sim, estão: perguntar, exemplificar, debater, acrescentar ao aprendizado, contribuir com os colegas, expor seu ponto de vista, curiosidade. Outros motivos extrínsecos são os trabalhos em 
grupos, responder perguntas e realizar atividades. Os motivos citados para a não participação são a timidez, medo de julgamento e medo de errar.

A partir da questão 4 - Quais os valores que consideras importante dentro de uma sala de aula, por parte do professor e por parte do aluno? - foram elencados as seguintes respostas, separando-se em (a) professor: respeito, didática, vontade de ensinar, organização; (b) alunos: participação ativa, colaboração, interesse, coleguismo, vontade de aprender; e (c) professores e alunos: respeito mútuo, cuidado com a diversidade, empatia, educação e disciplina. Esses pontos podem ser observados nos seguintes exemplos:

D 5, Física, $3^{\circ}$ semestre: Acredito que é de extrema importância uma relação de reciprocidade entre ambos, por parte do professor a humildade e sensibilidade de entender o lado do aluno como quem está aprendendo e terá dúvidas e dificuldades que podem ser consideradas 'tolas' e do aluno em ter empenho e procurar aprender o conteúdo.

D 6, Biologia, $7^{\circ}$ semestre: O princípio do respeito mútuo é o mais importante para todos os participantes da sala de aula, ele inclui o saber ouvir e saber explicar e argumentar.

A última questão, a número 5 - O que você entende por cooperação? Você acredita que coopera em sala de aula? Se sim, como? Se não, por que? - é espelhada no seguinte quadro:

Quadro III - Respostas à questão 5.

\begin{tabular}{|c|c|c|c|c|c|}
\hline Disciplina & Sim & Não & Depende & $\begin{array}{c}\text { Não } \\
\text { respondeu }\end{array}$ & $\begin{array}{c}\mathbf{N}^{\circ} \\
\text { alunos }\end{array}$ \\
\hline D1 & 11 & 2 & 1 & 4 & 18 \\
\hline D2 & 18 & 1 & 2 & 0 & 21 \\
\hline D3 & 8 & 2 & 0 & 0 & 10 \\
\hline D4 & 7 & 0 & 1 & 0 & 8 \\
\hline D5 & 33 & 3 & 0 & 2 & 38 \\
\hline D6 & 12 & 0 & 0 & 0 & 12 \\
\hline D7 & 18 & 1 & 0 & 1 & 20 \\
\hline
\end{tabular}

Fonte: Organizado pela autora.

Os fatores citados considerados como cooperativos são: lendo os textos, dando sugestões, contribuindo com discussões, colaborando com os colegas, respeitando ao professor e colegas, realizando atividades, dividindo experiências, apoio afetivos, ajuda mútua. $\mathrm{E}$, entre os fatores citados para a não cooperação estão: alvo de bullying, timidez, aulas sem estímulos à participação, falta de interesse, não saber o suficiente e dificuldade de socializar. Como exemplos, temos:

D 1, Física, $2^{\circ}$ semestre: $A$ cooperação pode se apresentar de várias formas, desde $o$ ato de permitir o bom andamento das aulas até propor uma discussão que possa contribuir com os temas propostos. 
D 1, Biologia, $4^{\circ}$ semestre: Cooperar é participar das atividades, auxiliar os demais e receber auxílio, dividir experiências e conhecimentos. Eu tenho por costume cooperar nas aulas e acredito que isso me revelou a vontade de ser professor.

D 7, Pedagogia, $2^{\circ}$ semestre: Eu entendo que o conceito de cooperação é quando muitas pessoas se juntam para realizar um objetivo na sala de aula da faculdade eu me sinto sozinha em relação a busca do meu conceito final, pois tudo depende somente de mim.

D 3, Ciências Sociais, $4^{\circ}$ semestre: Entendo cooperação como o esforço coletivo para a realização de um objetivo. Acredito que não há grande cooperação em sala de aula, pois, me geral, as aulas são conduzidas de forma que não há estimulo para mostrar interesse entre os alunos, bem como, em alguns casos, pouco interesse dos próprios alunos.

\section{Dados questionário final dos estudantes}

Esse segundo questionário foi aplicado ao final do semestre com as mesmas sete turmas iniciais e obtivemos 80 respondentes. Como já referido, este decréscimo se deu devido ao fato de ter estudantes que não estavam mais cursando as disciplinas, outros que já haviam sido aprovados e não compareceram aos encontros finais.

O questionário final também foi composto por cinco questões, sendo quatro dissertativas e uma objetiva, que visam compreender a avaliação dos estudantes dos seus processos de ensino e aprendizagem vivenciados na disciplina específica que foram pesquisados, como percebem que aprendem melhor, a sua participação efetiva em sala de aula com professores e colegas nas distintas disciplinas, os valores que compuseram as salas de aula e o que os conhecimentos específicos da disciplina pesquisada agregaram a sua formação.

A primeira questão solicitava 1 - Descreva seu processo de aprendizagem na disciplina durante o semestre. A maioria dos alunos considera a sua aprendizagem como positiva, citando como fatores: estudos e leituras, debates em sala de aula, dinâmica e atividades (trabalhos em grupos, pesquisa, trabalhos individuais, resenhas), didática dos professores, autonomia e empatia. Um dos fatores de destaque é a indicação da questão prática como potencializadora por parte dos estudantes. Como fatores negativos, que pesaram nas aprendizagens, apontam: falta de empenho pessoal, cansaço, falta de didática de professores, falta de familiaridade com conteúdos, problemas de saúde e pessoais. Para ilustrar, apresentamos os seguintes recortes:

D1, Artes Visuais, $6^{\circ}$ semestre: Através das conversas, leituras, dinâmicas e atividades propostas em aula foi possível aprender o conteúdo proposto. A professora utilizou métodos que tornaram mais fácil o processo de ensino e aprendizagem. 
D 2, Biologia, $10^{\circ}$ semestre: Foi algo muito prazeroso e fácil. Troca com a professora, monitor e colegas é muito enriquecedor. Aprendi muito fazendo.

D 4, Pedagogia, $5^{\circ}$ semestre: Minha aprendizagem neste semestre se deu muito através do contato humano, conversas francas entre alunos e professores, onde foram contemplados todas ideias, construções e vontades.

D 6, Matemática, $6^{\circ}$ semestre: Leitura de textos, conversas durante a aula, explicações da professora que me fizeram refletir sobre os tópicos, visita às escolas e reflexões sobre as práticas observadas.

D 5, História, $2^{\circ}$ semestre: Sinceramente, meu processo de aprendizagem foi nulo ou próximo disso. Ainda não entendi a necessidade de tudo o que foi dito nessa sala de aula.

D 7, Pedagogia, $2^{\circ}$ semestre: A minha aprendizagem foi muito complicada porque em muitas aulas não pude estar presente, por motivo de dificuldade e contratempo.

A questão 2 era: Em que momentos você julga que aprendeu melhor - aulas expositivas, trabalhos em grupos, seminários? Outros? Relate uma experiência que consideras exitosa. Nessa questão foram citados como práticas que promoveram mais aprendizagens as aulas expositivas com debates, análises de textos em sala de aula, trabalhos em grupos, pesquisas, dinâmicas e debates. Além desses apareceram trabalho de observação e análise, temais atuais, apresentações de trabalhos e uso de exemplos. Um dos destaques foi a inclusão de trabalhos práticos, apontado como fator de aprendizagem por quase todos os alunos.

Ilustrando, temos alguns recortes:

D1, Física, $2^{\circ}$ semestre: Trabalhos em grupo, sem dúvida. A melhor aula foi a de estereótipos onde fomos divididos em grupos e tínhamos que tratar o outro apenas da maneira que estava escrito em sua testa.

D 2, Biologia, $10^{\circ}$ semestre: Discussão em pequenos grupos e depois no grande grupo, coordenado/mediado pela professora. Mais proveitoso ainda quando era sobre uma prática realizada anteriormente. Exemplo, a avaliação da leitura do livro escolhido.

D 4, Pedagogia, $5^{\circ}$ semestre: Sempre aprendo melhor quando existe um diálogo aberto, honesto, em um lugar seguro, onde as angústias, vontades e 'necessidades' de aprender são consideradas e não julgadas. Nossas rodas de conversa são sempre exitosas.

D 5, Matemática, $2^{\circ}$ semestre: Acredito que foi quando comecei a ler alguns textos para escrever o texto que seria a avaliação final, pois foi quando me senti mais motivado e comecei a conversas mais com os colegas sobre $o$ assunto.

D 5, Matemática, $2^{\circ}$ semestre: Acredito que o momento no qual mais aprendi foi durante as trocas de ideias com o professor e com os outros alunos.

D 6, Biologia, $4^{\circ}$ semestre: A cadeira traz os conteúdos de forma dinâmica e integrada. A qualidade das aulas está justamente nessa pluralidade, todavia, as avaliações com viés prático são bastante esclarecedoras. 
D 6, Pedagogia, $1^{\circ}$ semestre: $A$ partir dos debates em aula, que saímos dos textos e conhecíamos a prática através de relatos da professora e dos colegas.

D 7, Pedagogia, $2^{\circ}$ semestre: Trabalho de pesquisa em grupo, quando tivemos que ir até o local estudado para pesquisar.

Para a questão 3 - Houve diferença na sua participação nesta disciplina em relação a outras? Se sim, qual(is)? - apresentamos as respostas no quadro a seguir, com os respondentes de sim ou não, e se essas diferenças foram positivas ou negativas.

Quadro IV - Respostas à questão 3

\begin{tabular}{|c|c|c|c|c|c|}
\hline Disciplina & Sim & Não & Positivo & Negativo & $\begin{array}{c}\text { Não } \\
\text { Respondeu }\end{array}$ \\
\hline D 1 & 7 & 3 & 7 & 0 & 0 \\
\hline D 2 & 19 & 1 & 18 & 1 & 0 \\
\hline D 3 & 4 & 1 & 4 & 1 & 1 \\
\hline D 4 & 8 & 0 & 8 & 0 & 0 \\
\hline D 5 & 5 & 2 & 5 & 1 & 1 \\
\hline D 6 & 7 & 5 & 0 & 0 & 0 \\
\hline D 7 & 9 & 10 & 0 & 0 & 1 \\
\hline
\end{tabular}

Fonte: Organizado pela autora.

Observa-se que a maioria dos estudantes acusa uma diferença da participação na disciplina pesquisada em relação a outras cursadas. Entre os fatores apontados, o que mais aparece nas respostas, considerado aqui como positivo é uma maior participação, mais frequência e elaboração de trabalhos com mais cuidado. E, como fator negativo, citam uma menor participação e baixo rendimento. Para exemplificar, citamos algumas das respostas:

D 1, Física, $2^{\circ}$ semestre: Se compararmos as Faceds que fiz, sim. Nesta disciplina fui bem mais participativo e tive maior entendimento.

D 3, Ciências sociais, $7^{\circ}$ semestre: Sim, pois não tive problemas particulares que coincidiram com o decorrer do semestre. Em 2018/1 estive muito disperso, sem conseguir focar nas aulas.

D 4, Pedagogia, $5^{\circ}$ semestre: Sim, esta é uma disciplina onde eu me sinto respeitada. Segura. Por isto, a vontade de participar é muito maior, foi a disciplina que moveu o meu semestre, me deu forças.

D 2, Educação Física, $8^{\circ}$ semestre: Acho que participei menos nas discussões do que o usual.

D 5, História, $2^{\circ}$ semestre: Sim, eu praticamente não participei dessa disciplina, enquanto me considero bem participativos nas outras.

D 7, Pedagogia, $2^{\circ}$ semestre: Não acredito que houve diferença. Tento participar da minha maneira, de todas as disciplinas. 
A questão 4 era: Marque com um $X$, dentro destes itens citados quais os que ocorreram em sala de aula. Essa questão era objetiva, visando realizar um levantamento dos observáveis que fizeram parte das salas de aulas, de acordo com o referencial teórico de Piaget (1973). Para tanto, segue o quadro com as respostas.

Quadro V - Respostas à questão 4.

\begin{tabular}{|l|c|c|c|c|c|c|c|}
\hline & D1 & D2 & D3 & D4 & D5 & D6 & D7 \\
\hline As regras foram estabelecidas de forma coletiva & 6 & 14 & 3 & 8 & 2 & 6 & 19 \\
\hline $\begin{array}{l}\text { O plano de estudos foi adequado ao que foi } \\
\text { proposto. }\end{array}$ & 9 & 19 & 4 & 5 & 6 & 11 & 17 \\
\hline $\begin{array}{l}\text { Você teve um sentimento de pertencimento a } \\
\text { turma. }\end{array}$ & 9 & 17 & 2 & 7 & 3 & 10 & 10 \\
\hline Você foi estimulado a participar em sala de aula. & 10 & 20 & 4 & 8 & 4 & 10 & 16 \\
\hline $\begin{array}{l}\text { Você teve autonomia em seu processo de } \\
\text { aprendizagem }\end{array}$ & 10 & 18 & 3 & 8 & 4 & 8 & 20 \\
\hline $\begin{array}{l}\text { Houve, da sua parte, observância aos acordos } \\
\text { estabelecidos (leituras, horários, prazos, etc). }\end{array}$ & 8 & 14 & 1 & 6 & 7 & 9 & 12 \\
\hline $\begin{array}{l}\text { Houve, da parte dos colegas e do professor, } \\
\text { observância dos acordos estabelecidos. }\end{array}$ & 9 & 17 & 4 & 6 & 6 & 12 & 11 \\
\hline Houve respeito entre colegas na sala de aula & 8 & 20 & 5 & 8 & 7 & 12 & 20 \\
\hline $\begin{array}{l}\text { Houve respeito entre professor e alunos na sala } \\
\text { de aula }\end{array}$ & 10 & 20 & 5 & 8 & 7 & 12 & 10 \\
\hline $\begin{array}{l}\text { Você sentiu satisfação com as trocas intelectuais } \\
\text { na sala de aula }\end{array}$ & 10 & 20 & 4 & 6 & 5 & 10 & 15 \\
\hline Foram realizadas atividades em grupos. & 10 & 19 & 2 & 4 & 0 & 12 & 20 \\
\hline $\begin{array}{l}\text { Foram feitos compartilhamentos de relatos e } \\
\text { experiências de vida }\end{array}$ & 9 & 20 & 5 & 8 & 5 & 12 & 19 \\
\hline $\begin{array}{l}\text { Houve aceitação de diversidade de pontos de } \\
\text { vista sobre os temas estudados }\end{array}$ & 10 & 19 & 4 & 8 & 6 & 11 & 18 \\
\hline Número de alunos & $\mathbf{1 0}$ & $\mathbf{2 0}$ & $\mathbf{5}$ & $\mathbf{8}$ & $\mathbf{7}$ & $\mathbf{1 2}$ & $\mathbf{2 0}$ \\
\hline
\end{tabular}

Fonte: Organizado pela autora.

A partir do quadro, podemos perceber a inclusão dos diversos observáveis, que são "[...] aquilo que a experiência permite constatar por uma leitura imediata dos fatos por si mesmo evidentes" (PIAGET, 1976, p. 46), como por exemplo, o estabelecimento de regras coletivas; observância dos acordos; aceitação da diversidade de pontos de vista, entre outros. Destaca-se que para Piaget, os observáveis são definidos através do que o sujeito crê constatar e não somente daquilo que é constatável. A maioria dos estudantes de todas as disciplinas confirmam que esses quesitos se fizeram presentes em sala de aula, com destaque ao respeito entre professor e alunos e entre colegas. De uma forma geral, podemos inferir que com esse conjunto de observáveis, que a cooperação se torna uma possibilidade de ocorrer em sala de aula, uma vez que vários dos elementos que a compõem estão presentes. 
A última questão, número 5 - O que essa disciplina acrescentou a sua formação? teve como maioria das respostas: nova visão sobre os temas, qualificação a partir da aprendizagem, contribuição à prática docente, afetos, conteúdos, aprendizagens e conhecimentos.

D 1, Física, $2^{\circ}$ semestre: Muito, pois vejo com muita importância o entendimento de como se dão os processos psicológicos das pessoas, principalmente se vinculados à prática docente.

D 2, Biologia, $4^{\circ}$ semestre: Me ensinou o tipo de professor que quero ser.

D 4, Pedagogia, $8^{\circ}$ semestre: Finalizo minha graduação compreendendo que é possível inovar em sala de aula, porém é difícil.

D 5, Matemática, $2^{\circ}$ semestre: Creio que todas as disciplinas estudadas na Faced são muito importantes na formação de futuros professores, e a [disciplina] me ajudou a olhar para a educação de pontos de vista diferentes, e tornou-me mais preparado para ser um bom educador.

D 6, Pedagogia, $1^{\circ}$ semestre: Me fez ter noção da realidade nas salas de aula e me ensinou que cada aluno tem sua singularidade e jeito de aprender.

D 6, Biologia, $4^{\circ}$ semestre: Fez eu perceber a importância de deixar o processo de educação o mais inclusivo possível. Cadeira que renovou meus sonhos e expectativas como futuro docente. O professor tem importância indiscutível em vários aspectos da formação da nossa sociedade, acredito que compreender essa importância seja o mais estimulado na cadeira.

\section{Dados questionário dos professores}

O questionário foi realizado com os professores no início do semestre. Esse instrumento continha sete questões dissertativas. Um dos docentes - D7 - não retornou o questionário. Seguem-se as questões e as respostas dos professores.

Para a questão 1 - Como você realiza o planejamento? - seis docentes referem considerar as sugestões dos estudantes para a elaboração dos seus planejamentos, seja através da avaliação do semestre anterior e/ou com as expectativas dos estudantes do semestre. Além disso, preocupam-se com a diversidade de materiais e atividades como integrantes do processo de ensino e aprendizagem.

À questão 2 - Como você trabalha? Quais as atividades que realiza? - respondem que efetuam uma diversidade de atividades, visando contemplar as aprendizagens. Todos os professores consideram as interações como um fator importante no contexto de sala de aula, sendo através de seminários, debates, trabalhos em grupos, jogos, dinâmicas, entre outros. 
Na questão 3 - Como são as avaliações? - referem que são realizadas de forma processual, considerando a participação do estudante durante o semestre, bem como, a frequência, a pontualidade, a qualidade dos trabalhos, a capacidade argumentativa, as atividades de campo, os trabalhos individuais e grupais. Todos os professores referem solicitar ao menos um trabalho escrito aos estudantes.

Quanto à questão 4 - Como você acredita que os seus alunos aprendem na sua disciplina? - os docentes partem do princípio de que o interesse é fundamental para o aprendizado. Referem que a aprendizagem precisa fazer sentido com as vivências dos alunos para auxiliar na compreensão dos conteúdos. O uso de metodologias ativas, tais como leituras e seminários, trocas com os colegas, compartilhamento de experiências e vivências; atividades em sala de aula como dinâmicas, jogos, pesquisas, etc. e a diversidade de materiais são citados como fatores fundamentais para as aprendizagens.

Na questão 5 - Qual a importância desta disciplina para a formação de professores? - houve unanimidade que cada uma delas contribui com a formação, seja no sentido de propiciar conhecimentos, como de práticas pedagógicas, além de compreensão de si mesmo e do mundo.

A questão 6 - Quais os valores que você considera importante dentro da sala de aula? - aparece em primeiro lugar o respeito. Seguem-se a empatia, o acolhimento a diversidade, o comprometimento, a equidade e a humildade.

E, a última, a questão 7 - Você considera que há cooperação entre os docentes? Entre os discentes? Como? - separamos as respostas para a compreensão: (a) Cooperação entre os docentes e; (b) Cooperação entre os discentes.

Em relação à Cooperação entre os docentes, um não respondeu e cinco disseram que sim. Todos os que responderam colocam que essa cooperação é pontual, realizada em cima de projetos, por afinidades pessoais ou teóricas. Como ilustrado nas seguintes respostas:

P3: Acredito que, de modo geral, a cooperação entre docentes é buscada quando projetos específicos são elaborados ou estão em desenvolvimento nas instituições educacionais ou em momentos de trabalho compartilhado por subgrupos de docentes. Há mais frequentemente cooperação entre participantes de grupos por afinidade [parcerias, corporações, militâncias] do que entre diferentes.

P4: Há cooperação. Tanto professores, professoras, acadêmicos e acadêmicas como 'qualquer pessoa' cooperam com quem tem afinidades e, segundo a afiliação teórica à qual estão ligados pelo estudo ou pela produção / construção de conhecimentos. 
P5: Creio que exista cooperação entre os docentes embora perceba que ainda são pontuais.

Em relação à Cooperação entre os estudantes, os professores também pontuam que existe, mas que essa precisa ser estimulada. Ou seja, nas suas respostas consideram que não é um processo espontâneo entre os estudantes, mas que requer uma atuação do professor, fomentando para que haja cooperação entre eles, seja através de atividades solicitadas, estudos em grupo, ou outras.

P1: Acho que metodologia de trabalho do professor é que possibilita os alunos a cooperarem.

P2: Do mesmo modo com os alunos, e, para isso, vejo o papel do professor e do monitor como fundamentais, dando o exemplo e estimulando a turma.

P3: Entre alunos de graduação em sala de aula, nos trabalhos em grupo, a cooperação é um desafio a ser proposto e acompanhado, seja nas tarefas conjuntas seja nas trocas verbais [ouvir e considerar o ponto de vista do outro]. A justaposição de partes isoladas de trabalhos repartidos é muito recorrente, inclusive com expectativas de avaliações individuais, quando nas apresentações em grupo.

P5: Quando são apresentadas oportunidades de trabalho colaborativo, são raros aqueles que demonstram resistência.

\section{Análise Geral}

A partir dos estudos e da coleta de dados, conseguiu-se formular algumas considerações a respeito do nosso problema de pesquisa, que era investigar como ocorre o método de cooperação nas trocas interpessoais durante a formação inicial de professores de cursos de licenciatura.

Com a análise dos dados, visando compreender a cooperação sob o ponto de vista do estudante no início do semestre, foi possível verificar alguns pontos, como a concepção epistemológica que os discentes têm de como eles aprendem; a importância que eles dão para as trocas entre colegas e professores em sala de aula; como eles se enxergam enquanto participantes em sala de aula; quais os valores que julgam pertinentes para comporem a sala de aula, tanto por parte dos professores, como dos colegas; e, compreender qual a concepção que têm de cooperação e se a praticam em sala de aula.

No que se refere ao questionário com os discentes ao final do semestre, ele nos possibilitou investigar como compreendem a sua aprendizagem em sala de aula; quais as metodologias que eles consideram exitosas para as suas aprendizagens; refletirem sobre a sua real e efetiva participação em sala de aula como componente de suas aprendizagens; 
verificar quais os valores que julgam importantes para comporem a sala de aula; e refletirem sobre as contribuições ou não das disciplinas cursadas para suas formações profissionais.

Também conseguiu-se conhecer um pouco mais do trabalho do docente, realizar um mapeamento das ações dos docentes e suas implicações para a cooperação em sala de aula. Verificar como realiza seu planejamento; a preocupação com a didática; as avaliações; o cuidado com aprendizagem dos alunos; a compreensão da contribuição da sua disciplina para formação; bem como os valores que julga importante de ter e manter em sala de aula. Além disso, investigamos os pontos de vista sobre a cooperação, tanto entre docentes, como entre discentes.

Todos estes dados foram computados e procurou-se estabelecer relações, constituindo um conjunto que possa ajudar a construir relações de cooperação entre os sujeitos. Um de nossos objetivos era, justamente, identificar observáveis de cooperação no processo de ensino e aprendizagem em disciplinas de licenciaturas. Assim, alguns elementos foram computados, tanto por parte dos alunos, quanto por parte dos professores, tais como os valores que compõem a sala de aula, as estratégias de aprendizagens, a existência de respeito mútuo, o interesse dos estudantes pelos temas de estudos, o cuidado dos professores com a inclusão, tipos de trocas realizadas e com o fomento à participação de todos, coordenando os diversos pontos de vista, entre outros pontos que mostram que esse pode ser um caminho profícuo para repensarmos alguns aspectos da educação, considerando a cooperação como um caminho para qualificar os processos de ensino e de aprendizagem.

Não se destacam, na pesquisa, a existência de vinculações afetivas entre os participantes, o que pode ser devido à diferença de cursos e de encontros em disciplinas específicas que duram somente um semestre, ou, levanta-se como hipótese, o fato de não haver continuidade nas relações, impeça a formação de vínculos. Esse ponto pode servir como um indicador para se refletir sobre o pertencimento ou a ausência desse, citada pelos estudantes de cada grupo vivenciado.

No que tange às atividades que, de acordo com os estudantes, podem fomentar a ocorrência da cooperação no processo de ensino e aprendizagem, a partir das respostas, mapeou-se, primeiramente, que para eles as trocas, tanto entre professores, como com colegas são fundamentais, seminários, aulas expositivas com debates, pesquisas, compartilhamento de experiências, temas atuais, práticas e trabalhos em grupos. O fator 
trabalhos práticos foi citado como um potencializador de aprendizagens pela maioria dos estudantes. Como fatores limitadores para a cooperação, citam a falta de empenho pessoal, cansaço, falta de didática de professores, dificuldade com os conteúdos, problemas pessoais.

Piaget (2002) refere que os métodos pedagógicos denominados ativos são os únicos capazes de desenvolver a personalidade intelectual. Estes implicam, como condição sine qua non, a intervenção do meio coletivo, que é tempo formador da personalidade moral e fonte de trocas intelectuais. Acrescenta que não há como constituir uma verdadeira atividade intelectual, fundamentada em ações experimentais e pesquisas espontâneas, sem que ocorra livre colaboração dos discentes entre si, entre docente e discente e, inclusive, entre docentes e docentes. A questão que julga essencial é que: "A atividade da inteligência requer não somente contínuos estímulos recíprocos, mas ainda, e, sobretudo, o controle mútuo e o exercício do espírito crítico, os únicos que conduzem o indivíduo à objetividade e à necessidade de demonstração" (PIAGET, 2002, p. 99).

Dessa maneira, refletir sobre as implicações para a formação de professores que decorrem do método de cooperação no processo de ensino e aprendizagem, nos permite verificar a formação que está sendo ofertada e as suas lacunas para que a cooperação seja realmente efetivada como um componente dos cursos.

Assim, procurou-se responder ao problema de pesquisa de como ocorre o método de cooperação nas trocas interpessoais durante a formação inicial de professores de cursos de licenciatura, a partir de observáveis e do mapeamento das atividades que nos ajudam a compor um conjunto desses elementos que se fazem necessários para que ocorra a cooperação. Conforme as respostas analisadas, detecta-se que há um potencial para que a cooperação possa ocorrer, tanto no que diz respeito aos observáveis elencados, como às atividades potencializadoras de trocas, pautadas em respeito mútuo.

Destaca-se que foi possível observar que existe cooperação, mas que esta é distante do conceito de Piaget (1973), que diz que a cooperação se encontra vinculada à interação entre sujeitos, requerendo vínculos e reciprocidade afetiva entre os componentes do processo de construção de conhecimento. Piaget afirma que a cooperação possui diversos níveis e é difícil alcança-la em sua totalidade.

É onde a cooperação implica um sistema de normas, diferindo da suposta livre troca cuja liberdade se torna ilusória pela ausência de tais normas. E é porque a verdadeira cooperação é tão frágil e tão rara no estado social dividido entre os 
interesses e as submissões, assim como a razão permanece tão frágil e tão rara em relação às ilusões subjetivas e ao peso das tradições (PIAGET, 1973, p. 111).

Mas, também, é importante atentarmos ao fato de que a cooperação é um processo e não um produto a ser ofertado, o que nos permite construí-la (CORBELLINI, 2019). De todo modo, os resultados da pesquisa apontam para fatores que podem fomentar ou inibir as relações de cooperação. Assim, elencam-se o interesse e a autonomia dos estudantes, as mediações dos professores, a didática, a construção de espaços que possibilitem a comunicação entre todos, atividades e avaliações formativas, manutenção de relações de respeito mútuo, ausência de coação, entre outros.

Entre os professores, fica claro que a cooperação é bastante pontual, sendo gerada por afinidades, temas afins, trabalhos pontuais, etc. Esse item nos conduz à necessidade de refletir por que há tão pouca cooperação entre os professores? A existência de uma grande diversidade de temas de interesses aliada à falta de espaços de trocas, uma vez que os encontros de professores se resumem à discussão de questões administrativas e não pedagógicas, podem ser alguns indícios para que a cooperação ocorra somente de forma pontual em encontros fortuitos a espaços e tempos delimitados.

Piaget (1973) afirma ser necessária a existência de, no mínimo, uma escala comum de valores intelectuais que possibilita a convivência dos sujeitos em um espaço e tempo comum. Esta convivência não é estática, e o equilíbrio é alcançado pela elaboração conjunta das regras, com base na reciprocidade, fundamentada em covalorização de todos os integrantes e equivale aos interesses sobre os temas afins que os participantes compartilharam.

Salienta-se a importância de incluir-se a cooperação nos processos de ensino e aprendizagem, pois ela permite trocas, confronto com diversos pontos de vista, descentração e equilibração, que propiciam enriquecimento de aprendizagens de todos os integrantes da sala de aula.

Assim, pontua-se que professores e estudantes formam um todo neste contexto, e como condição para que os sujeitos alcancem a condição de cooperar, - é necessário que estas relações sejam equiparadas, ou seja, entre pares. Assim, progressivamente, o método da cooperação pode ser construído em sala de aula. Compete ao professor propiciar espaços que permitam formas de relativizar os pontos de vista, incentivando a coordenação destes diversos pontos de vista, visando à construção da cooperação. $O$ 
professor, desta maneira, permanece indispensável ao processo de ensino-aprendizagem. Com base nessa investigação, corrobora-se a necessidade de superação de práticas individualistas e competitivas, colocando em seu lugar práticas de trabalhos em grupo e cooperativas no contexto educacional e da sociedade contemporânea. Compete incrementar-se estratégias para a construção de uma coletividade, de relações cooperativas, com regras e escalas de valores definidas por todos, o cuidado com a conservação dos acordos, mediações como facilitadoras das relações, entre outras.

\section{Considerações Finais}

A pesquisa que originou esse artigo procurou colaborar com a reflexão sobre a cooperação em salas de aula, acreditando que essa via pode ser um instrumento profícuo de aprendizagens coletivas que são tão urgentes no nosso contexto atual. A pandemia, de certa maneira, escancarou o individualismo presente nas relações e a necessidade de um coletivo para a sobrevivência de todos nós. Esse coletivo, pode se mostrar no cotidiano, nos cuidados necessários em prol de evitar contágios, como também se mostra na necessidade de trocas intelectuais entre os pesquisadores de todo o planeta para a erradicação do vírus. Ao mesmo tempo, observa-se como os indivíduos, tampouco, aprenderam a trabalhar de forma cooperativa e do quão urgente e desafiador é que aprendam a fazê-lo.

Acredita-se na importância do método da cooperação no contexto da educação como promotora de sujeitos autônomos, comprometidos com o seu 'espaço e tempo'. Acreditase, ainda, que uma educação de qualidade socialmente referenciada só é possível se for pautada entre sujeitos cooperativos, que interajam de forma a construir uma cidadania plena. Como afirma Piaget (1998, p. 69): “Há, pois, uma cooperação intelectual paralela à cooperação moral, e é por isso que a educação da solidariedade é tanto assunto de inteligência quanto de conduta". Aqui, destaca-se que o autor se refere à solidariedade interna, que repousa sobre a cooperação; distinguindo-a da externa, que repousa sobre as coerções.

Piaget (1973) apresenta a cooperação como uma relação interindividual que representa o nível mais alto de socialização e que é promovido pelo desenvolvimento e promotor de desenvolvimento. Ao abarcar a cooperação como método pontua, ao mesmo 
tempo, o processo e o equilíbrio dinâmico, diferenciando da coação. Aponta que os compromissos em relação à coação têm destino certo, enquanto aqueles assumidos em relação à cooperação são caminhos abertos a novas possibilidades.

Desta forma, aponta-se o estudo da interdisciplinaridade como uma das necessidades das sociedades. Este tema não foi contemplado na pesquisa, mas julga-se um tema que carece de maiores aprofundamentos e que está ligada à cooperação entre pares; e pode acompanhar a formação dos docentes no mundo contemporâneo. Piaget (1998) aponta para a existência de uma solidariedade intelectual entre os indivíduos e presume que essa se encontra nos seus primórdios. Como refere o autor:

\begin{abstract}
A solidariedade intelectual que, no entanto, é o meio vital da própria razão e que produziu essa realidade espantosa que é a ciência, ainda está apenas no início de suas conquistas, e um dos problemas centrais da educação internacional é fazê-la reinar inclusive nos espíritos individuais (PIAGET, 1998, p. 68-69).
\end{abstract}

Destacando-se alguns fatores que conseguimos inferir a partir dessa pesquisa, como a necessidade do professor de atuar neste processo, auxiliando na construção do método de cooperação, finaliza-se e afirma-se, em conjunto com Piaget (1998), que a cooperação é efetivamente criadora, ou que ela é um fator indispensável ao processo de ensinoaprendizagem para a constituição plena da razão do ser humano. Desta forma, competenos dedicar o olhar sobre este fenômeno, investigá-lo e procurar, cada vez mais, novas e melhores maneiras de incorporá-lo à educação e à sociedade como um todo.

\title{
Referências
}

CAMARGO, L.; BECKER, M. L. O Percurso do conceito de cooperação na Epistemologia Genética. Educação e Realidade, Porto Alegre, v. 37, n 2, p. 527-549, maio/ago. 2012. Disponível em http://seer.ufrgs.br/educacaoerealidade/article/viewFile/17341/19402.

CAMPOS, F. A. et al. Cooperação e aprendizagem on-line. Rio de Janeiro: DP\&A, 2003.

CORBELLINI, S. BNCC: NOS TRILHOS DO TREM. Revista ENSIN@ UFMS, Três Lagoas/MS, v. 1, n. 5, p. 1-163, dezembro 2020. Disponível em:

https://periodicos.ufms.br/index.php/anacpt//article/view/11311 Acesso em: 20 de janeiro de 2021.

CORBELLINI, S.; BECKER, M. L. R. Mapas de Trocas Intelectuais: representações para cooperação na educação a distância. RENOTE. Revista Novas Tecnologias na Educação (UFRGS, online), v. 17, $n^{\circ} 13$, p. 31-40, 2019. 


\section{ENSIN@UFMS 2021}

HARASIM, L. et. al. Learning Networks: a Field Guide to Teaching and Learning Online. London: Mit Press, 2000.

ISOTANI, S. Desenvolvimento de ferramentas no iGeom: utilizando a geometria dinâmica no ensino presencial e a distância. Dissertação Apresentada ao Instituto De Matemática e Estatística da Universidade de São Paulo, 2009. Disponível em:

http://www.cs.cmu.edu/ sisotani/mestrado/dissertacao.pdf . Acessado em: 20.11.13

KENSKI, V. M. Educação e Tecnologias: o novo ritmo da informação. 4 ed. Campinas: Papirus, 2007.

KENSKI, V. Tecnologias e ensino presencial e a distância. Campinas, SP: Papirus, 2003.

MONTAGERO, J. e MAURICE-NAVILLE, D. Piaget ou a inteligência em evolução. Porto Alegre: Artes Médicas, 1998.

PALLOFF, R. M.; PRATT, K. Construindo comunidades de aprendizagem no ciberespaço: estratégias eficientes para a sala de aula on-line. Tradução Vinícius Figueira. Porto Alegre: Artmed, 2002.

PIAGET, J. Problemas Gerais da Investigação Interdisciplinar e Mecanismos Comuns. Portugal: Oficinas Gráficas da Livraria Bertrand, 1970b.

PIAGET, J. Estudos sociológicos. São Paulo: Companhia Editora Forense, 1973.

PIAGET, J. Aprendizagem e conhecimento. Rio de Janeiro: Freitas Bastos, 1974.

PIAGET, J. A equilibração das estruturas cognitivas. Rio de Janeiro: Zahar, 1976.

PIAGET, J. Sobre a pedagogia. São Paulo: Casa do Psicólogo, 1998.

PIAGET, J. Para onde vai a educação? 16 ed. Rio de Janeiro: José Olympio, 2002.

\section{NOTAS}

\section{IDENTIFICAÇÃO DE AUTORIA}

Silvana Corbellini. Doutora em Educação. Professora Adjunta da Universidade Federal do Rio Grande do Sul, Faculdade de Educação. Departamento de Estudos Básicos. Porto Alegre, RS, Brasil.

E-mail: silvanacorbellini@gmail.com

(i) https://orcid.org/0000-0002-3335-0387

\section{AGRADECIMENTOS}

Não se aplica.

\section{FINANCIAMENTO}

Não se aplica. 


\section{CONSENTIMENTO DE USO DE IMAGEM}

Não se aplica.

\section{APROVAÇÃO DE COMITÊ DE ÉTICA EM PESQUISA}

Não se aplica.

\section{LICENÇA DE USO}

Autores mantêm os direitos autorais e concedem à revista ENSIN@ UFMS - ISSN 2525-7056 o direito de primeira publicação, com o trabalho simultaneamente licenciado sob a Licença Creative Commons Attribution (CC BY-NC-SA 4.0), que permite compartilhar e adaptar o trabalho, para fins não comerciais, reconhecendo a autoria do texto e publicação inicial neste periódico, desde que adotem a mesma licença, compartilhar igual.

\section{EDITORES}

Eugenia Brunilda Opazo Uribe, Gerson dos Santos Farias.

\section{HISTÓRICO}

Recebido em: 23/04/2021 - Aprovado em: 11/10/2021 - Publicado em: 06/12/2021.

\section{COMO CITAR}

CORBELLINI, S. Cooperação: Um Método Piagetiano na Formação de Professores. Revista ENSIN@ UFMS, Três Lagoas, v. 2, n. 6, p. 173-197. 2021. 